\title{
Implementation of Discovery Learning Factor Analysis in Transforming Learning Achievement Through Stimulus Organism Response Theory
}

\author{
Suryadi*, Ludfi Djajanto \\ Accounting Department \\ State Polytechnic of Malang, Indonesia \\ Malang, Indonesia \\ *suryadipolinema@yahoo.com, ludfimlg@yahoo.com
}

\begin{abstract}
The Discovery Learning method in collaboration with the Stimulus Organism Response Model (SOR) can explain the learning model and explain how the stimulus is captured by the five senses, then felt, causing a response to something. Whereas the discovery method with a lot of manifest causes discrepancies in the usual regression model analysis, so that the regression model constructs obtained are less suitable or less precise. To overcome this imprecision or deficiency, factor regression analysis can be used to overcome cases of multicollinearity. Factor analysis is a combination of factor analysis techniques and regression techniques. The purpose of this study was to obtain a new construct of discovery learning through the concept of SOR to improve learning achievement from the manifest variable of motivation. The object of research is marketing learning in class 1 in 2 study programs of the Department of Accounting with 114 respondents. The factor analysis formed is a new variable construct with the name New discovery motivation \& New discovery teamwork, with the last Factor Regression construct after the stimulus is P2 (New Performance $)=3.443+[(\mathbf{0 . 0 8 9} *$ (Newdiscoverymotivation $)+$ $9.11 *$ (Newdiscoveryteamwork)]. The results of the study prove that the individual relationship level of $57.9 \%$ and collectively $6.1 \%$ is good enough to achieve dimensional influence and it is evident that new constructs provide increased achievement.
\end{abstract}

Keywords—discovery, motivation, learning, stimulus

\section{INTRODUCTION}

Inquiry is a dynamic process to become open to magic and confusion and come to know and understand words [1]. Inquiry learning activities can be carried out through inquiry-based learning, discovery learning, case studies, problem-based learning, project-based learning, and so on. The existing learning model concludes that contractive learning methods can use problem stimulation and focus on students. The substitution of learning models develops in accordance with scientific learning which is closely related to involving observation, including: inquiry learning, discovery-based learning, problem-based learning, and other relevant models [2]. In this study, researchers used the concept of SOR [3]. The
SOR model is a model that explains how a stimulus is captured by the five senses as an organism, and then felt, resulting in a response. It is very relevant to be used by researchers as a reference for research and development of discovery learning type scientific learning models to change attitudes / motivation and learning outcomes of business computer applications. At the implementation stage the discovery learning model consists of several stages, including stimulation / experience, problem statement, data collection, data analysis, processing, verification and generalization (drawing conclusions / generalizations). To attract students' attention and motivation can be done by (a) reviewing the design and preparation of teaching materials and learning objectives, (b) designing methods to be used, (c) designing the use of simple language, curiosity students with the subject matter given, (f) designing and determining forms of verbal or nonverbal praise for students who show attention and motivation to students who pay attention and have good learning motivation, (g) design various learning methods to arouse student attention and motivation, (h) designing assignments / jobs that can build student attention and motivation.

Lecturer needs to ensure that each student acquires knowledge and skills that are in line with their learning objectives, and creates equal opportunities for students to actively seek, acquire, and process the acquisition of their learning. To produce active students, it is necessary to pay attention to: (a) review and determine teaching materials and learning objectives that require student activity, (b) design forms of active student learning, (c) design an atmosphere of questions and answers / (discussion) about teaching materials, (d) designing the task of finding and reading teaching materials and relevant sources individually or in groups (if needed, the lecturer can become a facilitator of the provision of teaching materials), and asks students to summarize and note things that are unclear to solve together, (e) designing learning methods and media that can motivate active learning. Therefore, SOR theory and factor regression analysis can be used as a tool to predict and have a good view and can find out the impact that will occur. This theory also bases the assumption that the 
causes of behavior change depend on the quality of the stimuli that communicate or the message conveyed to the organization. This study aims to expand the organizational response stimulus model (SOR) to the context of discovery-specific scientific learning to validate the influence of the motivation dimension on changes in achievement [4]. Data analysis uses Factor Regression Analysis to form the best constructs, rather than the motivation dimension that will be formed as a latent variable, whether it is appropriate and has been tested as a stimulus model in scientific learning type discovery. Whether the motivation dimension will be formed as a latent variable is appropriate and has been tested as a stimulus model in discovery learning. Whether students can find new things as phenomena that need to be reviewed for stimuli and responses to new constructs, this evidence is important to find and prove that the manifestations of motivation have an effect on achievement so that fewer factors are formed.

\section{LITERATURE REVIEW}

\section{A. Previous Research}

So far, there have been many studies examining discovery learning models and problem-based learning models for problem solving abilities. Among others are:

- The effectiveness of the discovery guide learning model on the ability to solve chemical problems. that the discovery guide learning model is effectively applied in chemistry learning for chemistry problem solving abilities [5].

- Analysis of the problem solving ability of class $X$ students in discovery learning based on student learning styles. This study produces a conclusion, namely: what is known and asked about the problem and explains the problem in its own sentence [6].

- Analysis of Mathematical Problem Solving Ability in terms of Motivation and Student Learning Styles, that: (a) the quality of learning can improve problem solving skills, (b) high learning motivation, and (c) student learning styles, visual, auditory, and kinesthetic are also different [7].

- Materials Science and Engineering with the title Influence of thematic learning models, learning styles, and reading skills on student learning outcomes. There are significant differences between thematic models and conventional models, between visual learning achievement and auditory learning styles; Between reading high and low Student achievement is influenced by the interaction between learning models and student learning styles [8].

- Mathematical Creative Thinking Ability of Elementary School Students in Inquiry Learning Based on Learning Styles, it is not enough (a) Kinesthetic students have creative learning styles, (b) Students with visual learning styles are less creative and not creative, (c)
Students with auditory learning styles are creative and very creative [9].

- Interaction of Learning Models and Learning Styles in Improving Student Learning Outcomes, Anova test results show a significant value. The interaction between the application of learning models and learning styles in improving student cognitive and affective learning outcomes is significant [10].

- The Influence of Reading Tests, Writing Skills and Learning Motivation on Indonesian Language Learning Outcomes of Elementary School Students. The result of the trial has a significance of 0.000 less than 0.05 , which means that there is an influence between learning motivation and learning outcomes of Indonesian elementary school students [11].

\section{B. Theoretical Review}

1) Stimiulus organisms and response in learning: Learning has an important role in human development, habits, attitudes, beliefs, goals, personality and perceptions. So learning is a mental and physical activity to obtain behavioral changes as an individual experience in interacting with their cognitive, affective, and psychomotor environments. These elements are interrelated so as to produce changes in behavior, namely: (a) Students, (b) Stimulus, (c) Memory, (d) Response. Based on these elements, the researcher is interested in studying student behavior learning towards the theory of perception developed by Mehrabian and Ruseel in 1974 regarding a model that explains the three main components, namely: stimulation, living things, and reactions to stimuli or often abbreviated as Stimulus, Organism, and Response.

Stimulus or stimulation can be controlled by the instructor and includes all components in the learning method / model. To understand individual behavior, it can be seen from two contradictory approaches, namely: (a) behaviorism: behavior patterns are formed through a process of habituation and reinforcement through conditioning or stimulus creation, can be Stimulus> Response or Stimulus> Organism> Response, (b) holistic or humanism : behavior formation sees that behavior has a final goal, meaning in terms of intrinsic aspects: intention, motive, determination from within the individual are the determining factors in giving birth to a behavior. Even in the absence of stimuli originating from the environment according to their hierarchical types, individual needs can be: a) physiological needs, b) security needs, c) need for affection or prestige or self-respect is usually a status symbol of selfactualization needs.

Organisms are defined as feelings and cognitive conditions that affect the relationship between stimulation and response [12]. Organism here refers to the internal processes that occur within a person, which consists of observing, feeling, and thinking. When stimuli are captured by the student's five senses, he will feel the stimulation by involving his feelings and thoughts, thereby determining the response to these 
stimuli. Perception itself can be defined as a process that begins with the exposure of stimuli to students, the emergence of attention to these stimuli, and ends with the students' interpretation of the existing stimuli.

Response is the end result of an internal process that occurs within the consumer and is the consumer's final decision. Consumers can make purchases, delay purchases, cancel purchases, or even avoid purchases. The SOR model is widely used by teachers / lecturers to find out how the relationship between stimuli given to students and student reactions to these stimuli through learning activities, questions, and assignments and exams. By studying this model, lecturers are expected to be able to create a learning model as an attractive stimulus so that it can be exposed by students. The stimulus is related to modules, delivery methods, learning methods, assignments, discussions, evaluations, and interesting feedback.

The learning model used as a guide for educators in planning and implementing the learning process is in accordance with the scientific learning approach and is very close to observation activities, including: inquiry-based learning, discovery learning, problem-based learning, projectbased learning, and other relevant models [13]. The advantages of learning models can be successful if educators are able to adapt and combine several learning models harmoniously and integrated. Discovery learning is a learning model that creates learning situations that involve students learning actively and independently in finding a concept or theory, understanding, and solving problems with educators as facilitators and mentors [14]. In this model, educators do not present learning material in the final form, but provide opportunities for students to find their identity using problem-solving techniques. The factors that influence learning are classified: (a) Learning stimuli are anything outside the individual that stimulates the individual to react or create learning, (b) The learning methods used by the lecturer are very influential and cause significant differences in the learning process, (c) Individual factors also greatly affect one's learning. Motivation variables are interdependent variables selected with question items a) online learning, b) proportional tasks, c) emodules, d) feelings of need, e) new enthusiasm, f) collaboration, work groups, g) challenging tasks, h) completion complete, i) various methods, j) learning stages, $\mathrm{k}$ ) creative, 1) finding solutions, $\mathrm{m}$ ) discussing, n) group assignments. While the measurement and evaluation of learning outcomes that have been owned by students, measuring the level of student achievement is done in two ways, namely: (a) Test Techniques: The initial test technique before giving the stimulus and the next test after giving the stimulus at mid-semester and end-semester levels. (b) Non Test Techniques: Information gathering or measurement in evaluation through observation, interviews and questionnaires. Non test techniques are more widely used to reveal psychomotor abilities and effective learning outcomes. The pre-stimulus test technique and subsequent tests after the stimulus at the mid semester and final semester levels.

\section{RESEARCH METHODS}

The method used in this research is a quantitative research method with a quasi-experimental design. The quasiexperimental design used was the matching only pre-test and post-test control group design. In this design, pre-test and posttest are carried out to determine the appropriate constructs of the variables that are formed. This research was conducted in two sample classes selected by nonprobability sampling technique with purposive sampling type [15]. Systematically, the independent variable is given the symbol Y (Motivation) and the dependent variable is given the symbol $P$ (Achievement). To obtain irritation from a collection of learning discovery learning data, simulation or stimulation in the form of an incomplete case-solving model is carried out so that students can find problems and solve them, and subsequently do data processing and verify the results between groups in one unit to conclude the discussion in order to obtain the respective score. -each. Furthermore, a factor analysis is carried out in order to explain the relationship structure between many variables in the form of factors or latent variables or constructed variables. The factor formed is a random quantity that previously could not be observed or measured or found directly from the $\mathrm{Y}$ (Motivation) variable amounting to 15 manifest. After the factors are formed, the regression equation is transformed in an effort to form equations before and after the stimulus so as to form new factor constructs that can be used in the effort to predict achievement on the implementation of discovery learning as a complete slice in the learning process.

\section{RESULTS AND DISCUSSION}

The results of sample measurements were carried out by validity and reliability tests (Cronbach Alpha) which showed that the frequency distribution of the questionnaire items was valid $(<0.05)$ and the usability test $(0.916>0.60)$, this shows that the understanding between the dimensions / question items is not multicollinearity, either However, between the free manifest and the free manifest and the relationship between the free manifest and the dependent variable, it is also necessary to do a multicollinearity test, even if the multicollinearity test results do not show symptoms of multicollinearity because the tolerance value of all manifestations is> 0.10. To form a Regression Factor Analysis in new constructions of various forms with non-independent variables, a factor analysis was carried out which in KMO and Barlett's Test of Sphericity of Sphericity of KMO 0.881 (KMO> 0.5). This shows the feasibility that the factor analysis is categorized well. On the examiner, the Bartlett test of togetherness obtained a significant value. (p. Value) of 0.0000 significant $<0.05$. After the identity crisis matrix, which means that the manifest is not mutually independent. For the process of forming the first selected factors to be analyzed, the variable Y (Motivation) consists of 15 manifest items to be random for 11 manifestations with the name motivation and 4 manifestations of the name of cooperation which are the dimensions of the new variable form. This new variable is the first factor $\left(\mathrm{F}_{1}\right)$ which consists of $\mathrm{Y}_{12}=0.823 ; \mathrm{Y}_{14}=09,766 ; \mathrm{Y}_{5}=0.731 ; \mathrm{Y}_{13}=0.691 ; \mathrm{Y}_{9}=$ 
$0.688 ; \mathrm{Y}_{8}=0.672 ; \mathrm{Y}_{10}=0.635 ; \mathrm{Y}_{11}=01.608 ; \mathrm{Y}_{4}=0.606 ; \mathrm{Y}_{2}=$ 0.549 ; and $\mathrm{Y}_{1}=0.537$, while the new variable the second factor $\left(\mathrm{F}_{2}\right)$ consists of $\mathrm{Y}_{6}=0.849 ; \mathrm{Y}_{7}=0.835 ; \mathrm{Y}_{15}=0.689 ;$ and $\mathrm{Y}_{3}=$ 0.587. If a tab is formed, it can be seen from table 1 below:

TABLE I. MANIFEST AND NEW NAME OF FACTOR VARIABLE :

\begin{tabular}{|l|c|c|}
\hline Manifest & Element/Factor & New name variable \\
\hline $\begin{array}{l}\text { Manifest } \\
\text { Mativat }\end{array}$ & 11 Element (Factor 1) & Motivation for discovery \\
\cline { 2 - 3 } & 4 Element (Factor 2) & New discovery teamwork \\
\hline
\end{tabular}

The naming of table 1 shows and explains individually which is the direction and tenacity of students to achieve the goal, namely finding to solve a case to get a solution. Motivation in groups has a positive influence that will affect individuals so that they can be more mature and have a more structured planning for learning. However, the finding that needs to be considered is that forming groups begins with the same feelings / perceptions to fulfill needs. The results of this research show that motivation arises out of necessity, then the determination of the same goals and finally the interaction, so that teamwork is realized. The first thing or the beginning, it turns out that the position is determined by the individual, who is the chairperson and who is the member, in the course of teamwork there will be interactions between members that allow for division (conflict), but conflict is temporary because the benefits of team work are greater, so that the members will adjusting for the common interest so that group changes towards the better will be easier to occur. For the manifest factor dimensions on the component score coefficient of each factor one $\left(\mathrm{F}_{1}\right)$ is New discovery Motivation and Factor $2\left(\mathrm{~F}_{2}\right)$ is New discovery team work is a variable to form the Factor Regression Equation where $\mathrm{P}_{1}$ (Achievements before) $=3.092$ $+0.095 *$ (Motivation for new discovery) $+0.136 *$ (New discovery teamwork) and $\mathrm{P}_{2}$ (Achievements after) $=3.443+$ $0.089 *$ (Motivation for new discovery) $+0,111 *$ (New discovery teamwork); This equation concludes that the free manifest $\mathrm{Y}$ (motivation) is the manifest. Thus $\mathrm{F}_{1}$ and $\mathrm{F}_{2}$ affect $\mathrm{P}_{1}$ (before) and $\mathrm{P}_{2}$ (after) simultaneously.

The individual test results and the results of the transformation of $\mathrm{P}_{1}$ and $\mathrm{P}_{2}$ show that the score of the factor model 1 is $\mathrm{P}_{1}$ and $\mathrm{P}_{2}$ before the stimulus is $\mathrm{t}$ (1.457) and significant (0.148) and the score of the Regression factor 2 is $\mathrm{P}_{1}$ and $\mathrm{P}_{2}$ before the stimulus is: $\mathrm{t}(2.085)$ and significant 0.039); whereas after the stimulus the regression factor score 1 was $\mathrm{P}_{1}$ and $\mathrm{P}_{2}$ was: $\mathrm{t}(1.686) \&$ significant $(0,095)$ and the regression factor score 2 was $\mathrm{P} 1$ and P2 were: $\mathrm{t}$ (2.097) \& significant $(0.036)$. The $\mathrm{T}$ value $(0.975 ; 113)$ is 1.96 . Variable Value of $\mathrm{T}$ Count Motivation of new discovery and new discovery team is outside the interval -1.96 and +1.96 . Based on the value of $\mathrm{T}$ count and $\mathrm{T}$ value $(0.975 ; 113)$ obtained, it can be said that the regression model contains the right two factors to the existing data. Overall, on the exposure to the results of the analysis, it can be denied that the regression equation obtained has met all the tests so that the application of the scientific learning model carried out in accordance with the concept of SOR and proven factor regression analysis stages can be used as a reference for collaborating between factor analysis and factor regression analysis to form or construct. new variables in the Discovery Learning Method collaborated with the Stimulus Organism Response Model in marketing management learning.

\section{CONCLUSIONS AND SUGGESTIONS}

Through the scientific type discovery learning stages and tests before and after the stimulus learning process, the frequency distribution of students can be traced and the implementation of factor regression analysis obtained a business computer application learning model that describes the relationship between the dimensions of learning motivation and achievement. The theory of Stimulus Organism Response and Learning Discovery has been able to form a new motivation variable, namely factor 1 is the motivation of discovery and factor 2 is the motivation of teamwork which has a significant effect on the learning outcomes of business computer applications, which increases more than the previous stimulus. The estimation result of the correct parameters is $\mathrm{P} 2$ (Achievements after $)=3.443+[(0.089 *$ Motivation for new discovery $)+(0.111 *$ New discovery teamwork $)]$. It is hoped that the next researcher can develop a regression factor model that is transformed by automatic regression to obtain information on students who need more intensive attention and motivation [16]. The elements of discovery and follow-up to the results of factor 1 with 11 manifest are determinants of motivation change in discovery to increase student achievement, while factor 2 with 4 manifest determines changes in team work motivation to improve student achievement. That the two new variables are ideal variables that need attention and can be used as a discovery type learning stimulus model to improve student learning achievement.

\section{REFERENCES}

[1] Galileo Educational Network, What is Inquiry? Questions \& ICT. 2004.

[2] I. Kusnadi, Guidelines for Making Textbook Teaching Materials According to the 2013 Curriculum. Surabaya, 2014.

[3] A. Mehrabian, "Pleasure-arousal-dominance: A general framework for describing and measuring individual differences in temperament," Curr. Psychol., vol. 14, no. 4, pp. 261-292, 1996.

[4] L. Yun-Long and L. Ren-Hou, "Discovery and learning of models with predictive state representations for dynamical systems without reset," Knowledge-Based Syst., vol. 22, no. 8, pp. 557-561, 2009.

[5] S. Nastiti and T.A.T.W.W. Sumarni, The Effectiveness of Learning Model Guided Learning Invention on Chemical Problem Solving Ability. Semarang: Semarang State University, 2012, 2012.

[6] E.B. Widiyanto, I. Isnarto, and A.N. Cahyono, "Mathematical Problem Solving Ability of Vocational School Students Reviewed from Self Regulated Learning in Selective Problem Solving (SPS) Assisted Learning Management System (LMS) Learning," Unnes J. Math. Educ. Res., vol. 10, no. A, pp. 171-180, 2021.

[7] W.N. Huda, H. Suyitno, and W. Wiyanto, "Analysis of Mathematical Problem Solving Abilities in Terms of Students' Motivation and Learning Styles," J. Prim. Educ., vol. 6, no. 3, pp. 209-217, 2017.

[8] L. Nurlaela, M. Samani, I.G.P. Asto, and S.C. Wibawa, "The effect of thematic learning model, learning style, and reading ability on the 
students' learning outcomes," in IOP Conference Series: Materials Science and Engineering, 2018, vol. 296, no. 1, p. 12039.

[9] I.M. Fathoni, I. Isnarto, and S. Haryani, "Mathematically creative thinking abilities students of elementary school on learning inquiry training based on learningstyle," J. Prim. Educ., vol. 7, no. 2, pp. 121$128,2018$.

[10] S.W. Oktari, H.T. Atmaja, and A.R. RC, "The Interaction of Learning Model and Learning Style in Improving Students Learning Outcomes," J. Prim. Educ., vol. 8, no. 5, pp. 206-216, 2019.

[11] T.B. Prakoso, R. Rustono, and E. Purwanti, "The Effects of Reading Test, Writing Skills and Learning Motivation Toward Learning Outcome of Bahasa Indonesia Subject in Students in Primary School," J. Prim. Educ., vol. 8, no. 1, pp. 1-9, 2019.
[12] H.-J. Chang, M. Eckman, and R.-N. Yan, "Application of the StimulusOrganism-Response model to the retail environment: the role of hedonic motivation in impulse buying behavior," Int. Rev. Retail. Distrib. Consum. Res., vol. 21, no. 3, pp. 233-249, 2011.

[13] R. Sani, Learning Innovations. Jakarta: Jakarta. Earth Literacy.

[14] D.J. Priansa, Student Management and Learning Models. Bandung: Bandung: Alfabeta, 2015.

[15] S. Sugiyono, "Educational Research Methods (Quantitative Approach, Qualitative and R \& D)," Bandung Alf., 2013.

[16] Suryadi, Development of e-module based on Scientific Learning Model Type Discovery Learning to Improve Attitude Change and Learning Outcomes of Business Computer Applications. 2020. 